\title{
Galectin-3- Mediated Transdifferentiation of Pulmonary Artery Endothelial Cells Contributes to Hypoxic Pulmonary Vascular Remodeling
}

\author{
Li Zhang ${ }^{a, b} \quad$ Yu-mei Lib,c Xi-xi Zenga,b Xiao-yan Wang ${ }^{d} \quad$ Shao-kun Chen ${ }^{a, b}$ \\ Long-xin Guib Mo-jun Lin ${ }^{a, b}$
}

aDepartment of Physiology \& Pathophysiology, Fujian Medical University, Fuzhou, ${ }^{\mathrm{b}}$ The Key Laboratory of Fujian Province University on lon Channel and Signal Transduction in Cardiovascular Disease, School of Basic Medical Sciences, Fuzhou, 'Fujian Center for New Drug Safety Evaluation, Fujian Medical University, Fuzhou, dDepartment of Physiology, Harbin Medical University, Daqing, China

\section{Key Words}

Pulmonary artery hypertension - Galectin-3 - Endothelial-mesenchymal transdifferentiation; vascular muscularity $\bullet$ Pulmonary artery endothelial cells

\begin{abstract}
Background/Aims: Vascular muscularity is a key event in vessel remodeling during pulmonary artery hypertension (PAH). Endothelial-mesenchymal transdifferentiation (EndMT) has been increasingly reported to play a role in disease occurrence. Galectin-3, a carbohydrate-binding protein regulates cell proliferation, differentiation, migration and neovascularization. However, whether galectin-3 controls endothelial cell transdifferentiation during the development of PAH is unknown. Methods: Rats were exposed to normoxic or hypoxic conditions (fraction of inspired $\mathrm{O}_{2} 0.10$ ) for $21 \mathrm{~d}$ to establish PAH models. Hemodynamic changes were evaluated through surgery of the right jugular vein and ultrasound biomicroscopy inviVue. And vessel pathological alterations were detected by H\&E staining. Galectin-3 (Gal-3)-induced pulmonary artery endothelium cell (PAEC) dynamic alterations were measured by MTT assays, Cell immunofluorescence, Flow cytometry, Real-time PCR and Western blot. Results: Our study demonstrated that Gal-3 was expressed in hypoxic pulmonary vascular adventitia and intima. The increased Gal-3 expression was responsible for hypoxic vessel remodeling and PAH development in vivo. Gal-3 was found to inhibit cell proliferation and apoptosis in cultured endothelial cells. Meanwhile endothelial cell morphology was altered and exhibited smooth muscle-like cell features as demonstrated by the expression of $\alpha$-SMA after Gal-3 treatment. Gal-3 activated Jagged1/Notch1 pathways and induced MyoD and SRF. When MyoD or SRF were silenced with siRNAs, Gal-3-initiated transdifferentiation in endothelial cells was blocked

L. Zhang and Y. Li contributed equally to this work.

\begin{tabular}{ll}
\hline Mo-jun Lin & Fujian Medical University \\
& No. 1 Xuefubei Road, Fuzhou, Fujian, 350122 (China) \\
& Tel. +86-591-22862429, Fax +86-591-22862429, E-Mail mjlin@mail.fjmu.edu.cn
\end{tabular}
\end{abstract}

\section{KARGER}




\section{Cellular Physiology Cell Physiol Biochem 2018;51:763-777

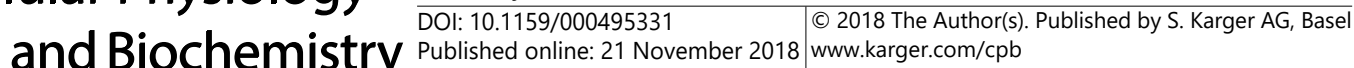 \\ Zhang et al:: Galectin-3 Regulates Endothelial Cell Transdifferentiation}

as indicated by a lack of $\alpha$-SMA. Conclusion: These results suggest that Gal-3 induces PAECs to acquire an $\alpha$-SMA phenotype via a transdifferentiation process which depends on the activation of Jagged1/Notch1 pathways that mediate MyoD and SRF expression.

\section{Introduction}

(C) 2018 The Author(s)

Published by S. Karger AG, Basel

Pulmonary arterial hypertension (PAH) is a malignant disease that can result in significant morbidity and mortality, with hypoxia known to be a contributing factor in the development of PAH pathogenesis. Chronic hypoxia is therefore a well- characterized experimental model for PAH and pulmonary vascular remodeling (PVR). Pulmonary vessel muscularization is a key event that results from increased numbers of pulmonary artery smooth muscle cells (PASMCs), leading to vascular remodeling and the onset of PAH. The increase in PASMCs can originate from increased proliferation, as well as other components, such as fibroblasts [1-2]. Recently, endothelial cells were shown to contribute to vascular remodeling though their transformation into mesenchymal or SM-like phenotype cells that then migrate into their underlying tissues. Other studies also indicated that endothelial cell transformation can occur in adult life during a number of diseases, including PAH [3], atherosclerosis [4] and wound healing [5].

Galectin-3 (Gal-3) affects the pathogenesis of many diseases, including heart failure and arteriosclerosis [6-7]. It belongs to a family of $\beta$-galactoside-binding lectins and plays an important role in cellular physiological and pathological processes, such as cell proliferation, adhesion, differentiation, angiogenesis, inflammation and fibrosis, all of which are important for the development of vessel remodeling and stiffness. Gal-3 has been shown to stimulate PASMC proliferation and fibrosis in PAH [8-9]. Additionally, Gal-3 inhibition alleviated the hypoxia-induced inflammatory response in PAEC and PASMC proliferation in humans [10]. However, the role of Gal-3 in pulmonary artery muscularization and PVR is uncertain. Thus, we wanted to explore whether Gal-3 was necessary for endothelial cell transformation in a rat model of PAH.

In this study, we investigated the role of Gal-3 expression in PVR of hypoxic rat PAH models. We further explored the possible mechanisms of Gal-3 function during the conversion of cultured endothelial cells into smooth muscle-like cells under hypoxic conditions.

\section{Materials and Methods}

\section{Reagents}

Galectin-3 was purchased from BioVision (San Francisco, USA). The Cycle TEST PLUS DNA Reagent Kit was obtained from BD Biosciences (Bedford, MA). DAPT and N-Lac were obtained from Selleck (Houston, USA). Anti-Galectin-3, $\alpha$-SMA, Jagged1, activated Notch1 and LC3A/B were purchased from Cell Signaling Technologies (Boston, USA), anti-Calponin and Osteoponin were obtained from BOSTER (Wuhan, China), and anti-SRF and MyoD were purchased from Proteintech (Wuhan, China). All primers and oligo nucleotides used in this study were synthesized by GenePharma Co., Ltd. (Shanghai, China).

\section{Lung Tissue Preparations}

Human lung specimens were obtained from Harbin Medical University Fourth Affiliated Hospital. Surgical interventions (lung transplantations, pulmonary lobotomy, or pneumonectomy) for PAH as well as other localized lung diseases were performed under the procedures approved by the Harbin Medical University Ethics Committee for the Use of Human Samples. Human lung specimens obtained from lobotomy or pneumonectomy of localized lung cancer were used as controls.

Male Wistar rats were provided by the Experimental Animal Center of Fujian Medical University, China. The use of animals was in accordance with the Guidelines and Principles of Laboratory Animal Care and Protocols of the Animal Care Committee of Fujian Medical University. Rats were exposed to normal and 


\section{Cellular Physiology Cell Physiol Biochem 2018;51:763-777 \begin{tabular}{l|l|l} 
and Biochemistry Published online: 21 November 2018 & $\begin{array}{l}\odot 2018 \text { The Author(s). Published by S. Karger AG, Basel } \\
\text { www.karger.com/cpb }\end{array}$ \\
\hline
\end{tabular} \\ Zhang et al.: Galectin-3 Regulates Endothelial Cell Transdifferentiation}

hypoxic environments with fractions of inspired $\mathrm{O}_{2}\left(\mathrm{FiO}_{2}\right)$ at 0.21 and 0.10 , respectively. Rats were housed in the same room for $21 \mathrm{~d}$ and then anesthetized prior to removal of the lungs, which were used for the following experiments.

\section{Hemodynamic Evaluation}

Rats were anesthetized, fixed and their right external carotid veins were stripped. PE-50 tubes were filled with heparin saline and connected to a pressure transducer that was then inserted into the right external carotid vein. Intubation was carried out to position the tube within the rat heart for physiological observation and was followed by immediate attachment of a 1.2 French pressure catheter. The baseline increase in the pulmonary artery pressure waveform stabilized before the Ppa levels were measured using a physiological recorded display.

\section{Ultrasound Biomicroscopy InviVue}

Rats were anesthetized and imaged using the Vevo 2100 Imaging System (Visual Sonics Inc., Toronto, Ontario, Canada) fitted with a $30 \mathrm{MHz}$ probe [11]. Stable images were obtained in the M, B, and Doppler modes, and the pulmonary arterial velocity time integral (PA-VTI) and pulmonary artery acceleration (PAAT) were measured.

\section{Hematoxylin-eosin (H\&E) Staining}

Rat and human lung tissues were immersed in 4\% paraformaldehyde for fixation and then sliced into tissue blocks. Tissues were dehydrated, cleared and embedded in paraffin wax. The wax blocks were cut into 3-5 mm thick sections. The morphologic changes in the vascular lung tissues were analyzed. The tissue sections were dried at $65^{\circ} \mathrm{C}$ and then were deparaffinized and rehydrated in graduated xylene and alcohol, respectively. The sections were stained with hematoxylin and eosin for $3 \mathrm{~min}$ and then dehydrated using a standard protocol with increasing percentages of alcohol, xylol, and balsam, as previously described [2, 12].

\section{In situ Hybridization (ISH)}

In situ hybridization was performed to detect Gal-3 mRNA using the Galectin-3 ISH Detection Kit. Briefly, rats were killed, and their lung tissues were immediately dissected and fixed in $4 \%$ paraformaldehyde in 0.1 M sodium phosphate buffer ( $\mathrm{pH}$ 7.2-7.6) with 0.1\% DEPC. Tissues were sliced into tissue blocks, dehydrated, cleared and embedded into paraffin wax blocks, which were then cut into 3-5 mm thick sections. Tissue sections were dried at $65{ }^{\circ} \mathrm{C}$ and then deparaffinized and rehydrated using graduated xylene and alcohol, respectively. Endogenous peroxidase activity was blocked with $30 \% \mathrm{H}_{2} \mathrm{O}_{2}$ and distilled water with $0.1 \%$ DEPC (1:10). Sections were treated with $3 \%$ citric acid and fresh diluted pepsin at $37{ }^{\circ} \mathrm{C}$ for 30 min to expose mRNA fragments. Sections were then fixed in 1\% paraformaldehyde in $0.1 \mathrm{M}$ sodium phosphate buffer $(\mathrm{pH}$ 7.2-7.6) containing $0.1 \%$ DEPC for $10 \mathrm{~min}$ at RT. After the sections were washed, prehybridization solution was added to each section in a wet box with $20 \mathrm{ml}$ of $20 \%$ glycerin for $4 \mathrm{~h}$ at $42{ }^{\circ} \mathrm{C}$. Samples were then incubated in hybridization solution overnight at $42^{\circ} \mathrm{C}$.

The target mRNA gene sequences of rat Gal-3 that were used in this study are as follows:

5'-CTTCCACTTTAACCCCCGCTTCAATGAGAA-3', 5'-AATAAATGGGGAAGGGAAGAAAGACAGTCA-3', and 5'-AAACCATTCAAAATACAGGTCCTGGTTGAA-3'.

The next day, sections were washed with 2X SSC for $10 \mathrm{~min}$ and $0.5 \mathrm{X}$ SSC for $15 \mathrm{~min}$, blocked at $37^{\circ} \mathrm{C}$ for $30 \mathrm{~min}$, and then incubated with rat biotin anti-digoxin at $37^{\circ} \mathrm{C}$ for $60 \mathrm{~min}$. Sections were washed with PBS, incubated with SABC at $37^{\circ} \mathrm{C}$ for $20 \mathrm{~min}$ and then incubated with biotin peroxidase for $20 \mathrm{~min}$ at $37^{\circ} \mathrm{C}$. Next, sections were visualized with 3, 3-diaminobenzidine (DAB) and counterstained using hematoxylin. Finally, hydrochloric acid alcohol differentiation and dehydration were performed on each of the sections.

\section{Cell Culture}

Pulmonary artery endothelial cells (PAECs) were purchased from ATCC Inc. Cells were cultured with DMEM containing 15\% FBS, with passages 3-5 used in later experiments. Cells were cultured in a humidified incubator (Thermo Fisher, Runcorn, Cheshire, UK) with $5 \% \mathrm{CO}_{2}$ at $37^{\circ} \mathrm{C}$ for normoxic conditions. A Tri-Gas incubator (Heal Force, Shanghai, China) was used to provide an atmosphere of $3 \% \mathrm{O}_{2}, 5 \% \mathrm{CO}_{2}$ and $92 \% \mathrm{~N}_{2}$ for hypoxic culture $[2,12]$. 


\section{Cellular Physiology Cell Physiol Biochem 2018;51:763-777 and Biochemistry \begin{tabular}{l|l} 
DOI: $10.1159 / 000495331$ & 2018 The Author(s). Published by S. Karger AG, Basel
\end{tabular}

\section{Immunofluorescence Assay}

Frozen sections or cells were plated in six-well glass chamber slides, and cell growth was arrested as described previously $[2,12]$. Briefly, tissues or cells were fixed with $4 \%$ paraformaldehyde and blocked. These slices were treated with $0.3 \%$ Triton and then incubated with Calponin and Osteopontin, $\alpha$-SMA or CD31 (1:100) antibodies overnight at $4^{\circ} \mathrm{C}$. Antibody staining was performed with Alexa 488-conjugated goat anti-rabbit IgG and anti-mouse IgG (1:100) at RT in the dark for $2 \mathrm{~h}$. 4',6-Diamidino-2-phenylindole (DAPI) was used to stain cell nuclei, and images were obtained using a Live Cell Station (DMI6000B, Leica, Germany).

\section{MTT}

PAECs were cultured in a 96-well plate (at a density of approximately $1 \times 10^{4}$ cells) and then treated with or without Gal-3 (5 $\mu \mathrm{M})$ for $7 \mathrm{~d}$ in DMEM containing 3\% FBS. 3-[4, 5-dimethylthiazol- 2-yl]-2, 5-diphenyltetrazolium bromide (MTT) was used to measure cell viability using the standard method as previously described [12-13].

Cell Cycle and DNA Analyses

PAECs were treated with or without Gal-3 $(5 \mu \mathrm{M})$ for $7 \mathrm{~d}$. We used the Cycle TEST PLUS DNA Reagent Kit to examine cell cycle alterations as previously described $[2,12]$.

\section{Transient Cell Transfection}

To knockdown Gal-3, MyoD and SRF, PAECs were transfected with small interfering RNAs, which were designed and synthesized by GenePharma using HieffTrans ${ }^{\mathrm{TM}}$ Liposomal Transfection Reagent (YEASEN, Shanghai, China). FAM-tagged nontargeted control siRNA (siRNC) was used as a negative control to optimize the efficiency of transfection. The siRNA sequences and the FAM-tagged nontargeted control sequences are listed below:

Galectin-3: (NM:012775) 5'-CCUCGCAUGCUGAUCACAATT-3',

MyoD: (NM:153301) 5'-UCUAUGAUGAUCCGUGUUUTT-3',

SRF: (NM:012775) 5'-GGCAAGGCGCUGAUUCAGATT-3', and

NC control: 5'-UUCUCCGAACGUGUCACGUTT-3'.

PAECs were starved with DMEM without serum for $24 \mathrm{~h}$ before treatment. Five microliters of HieffTrans $^{\mathrm{TM}}$ Liposomal Transfection Reagent was diluted into $50 \mu \mathrm{l}$ of serum-free Opti-MEMI medium, and the solution was allowed to stand for $5 \mathrm{~min}$. One hundred picomoles of siRNA was then dissolved into $50 \mu \mathrm{l}$ of serum-free Opti-MEMI medium, and this mixture was mixed for another $20 \mathrm{~min}$ at RT. The cell medium was replaced with DMEM, and the siRNAs and transfection reagent were added to the cells and allowed to incubate for $6 \mathrm{~h}$. Controls were prepared in the same way using transfection reagent alone (mock) and siRNC. The transfection medium was discarded, and cells were cultured in DMEM containing 3\% FBS with Gal-3 $(5 \mu \mathrm{M})$ for $48 \mathrm{~h}$. Protein levels were determined using Western blot analysis.

\section{Real-time PCR}

After appropriate treatment, total cellular RNA was isolated from PAECs using TRIzol according to the manufacturer's instructions (TaKaRa). Gal-3 and $\beta$-actin levels were quantified using a qRT-PCR detection kit (TaKaRa) and then subjected to real-time PCR with SYBR Green I. The amplification was carried out using an Applied Biosystems 7300 real-time PCR system (Applied Biosystems) as described previously [2]. The primer sequences were as follows:

Galectin-3-F: 5'-CCTTCCGGACCACTGAATGT-3',

Galectin-3-R: 5'-TGGAAGGCGACATCATTCCC-3',

$\beta$-actin-F: 5'-TCCGTGACATCAAGGAGAAGC-3', and

$\beta$-actin-R: 5'-GCACCGTGTTGGCGTAGAG-3'.

\section{Western Blot}

For Western blot analysis, total proteins were extracted, and protein concentrations were determined by a bicinchoninic acid protein assay (Pierce, Rockford, IL) with bovine serum albumin (BSA) as the standard. Fifty micrograms of protein from each sample was fractionated on a $10 \%$ SDS-polyacrylamide gel as described previously [12-13].

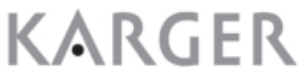




\section{Cellular Physiology and Biochemistry \begin{tabular}{l|l} 
DOI: 10.1159/000495331 & 2018 The Author(s). Published by S. Karger AG, Basel \\
(c) & www.karger.com/cpb
\end{tabular}

Data Analysis

All data are presented as the means $( \pm$ SEM). More than two groups of continuous variables were present in this study; therefore, one-way analysis of variance (ANOVA) followed by Bonferroni's or Dunnett's post hoc test was used for multiple comparisons. A two-tailed value of $\mathrm{p}<0.05$ was considered statistically significant. Data were analyzed using GraphPad Prism 5.0 and SPSS 14.0 software.

\section{Results}

\section{Gal-3 regulates pulmonary arterial pressure}

To determine the possible role of Gal-3 in hypoxia-induced PAH, the Gal-3 inhibitor, L-Nac $(5 \mathrm{mg} / \mathrm{d}$, every other day) was administered to hypoxic rats. After 3 weeks, pulmonary artery pressure signals were monitored continuously on an RM6240 polygraph (Chengyi, China) through a right jugular vein cannulation. The results indicated that hypoxia-induced high pressure in the pulmonary artery was alleviated by L-Nac application compared to untreated hypoxic rats (Fig. 1A). Using Ultrasound Biomicroscopy InviVue analysis, the results also showed that both PATV and PATVI indexes were ameliorated in L-Nac administered rats (Fig. 1B-D).

\section{Gal-3 is expressed in PAECs and is involved in PVR}

To determine whether Gal-3 was implicated in PVR, lung samples from PAH patients and hypoxic rats were collected and assessed by H\&E staining. The results showed that thickened vessel walls were present in both human PAH (Fig. 2A) and hypoxic rats (Fig. 2B), while hypoxic rats treated with L-Nac displayed improved PVR (Fig. 2B). To localize Gal-3 expression in the lung vessels, ISH was performed on lung tissues from patients with $\mathrm{PAH}$ and hypoxic rats. The results showed strong intensity staining for Gal-3 in pulmonary artery intimal and adventitial walls in PAH tissues (Fig. 2C and D). As shown in Fig. 2E, there was intense staining for Gal-3 in the intimal and adventitial walls of hypoxic rats, while L-Nac weakened this intensity. By contrast, the control rat sections displayed inapparent

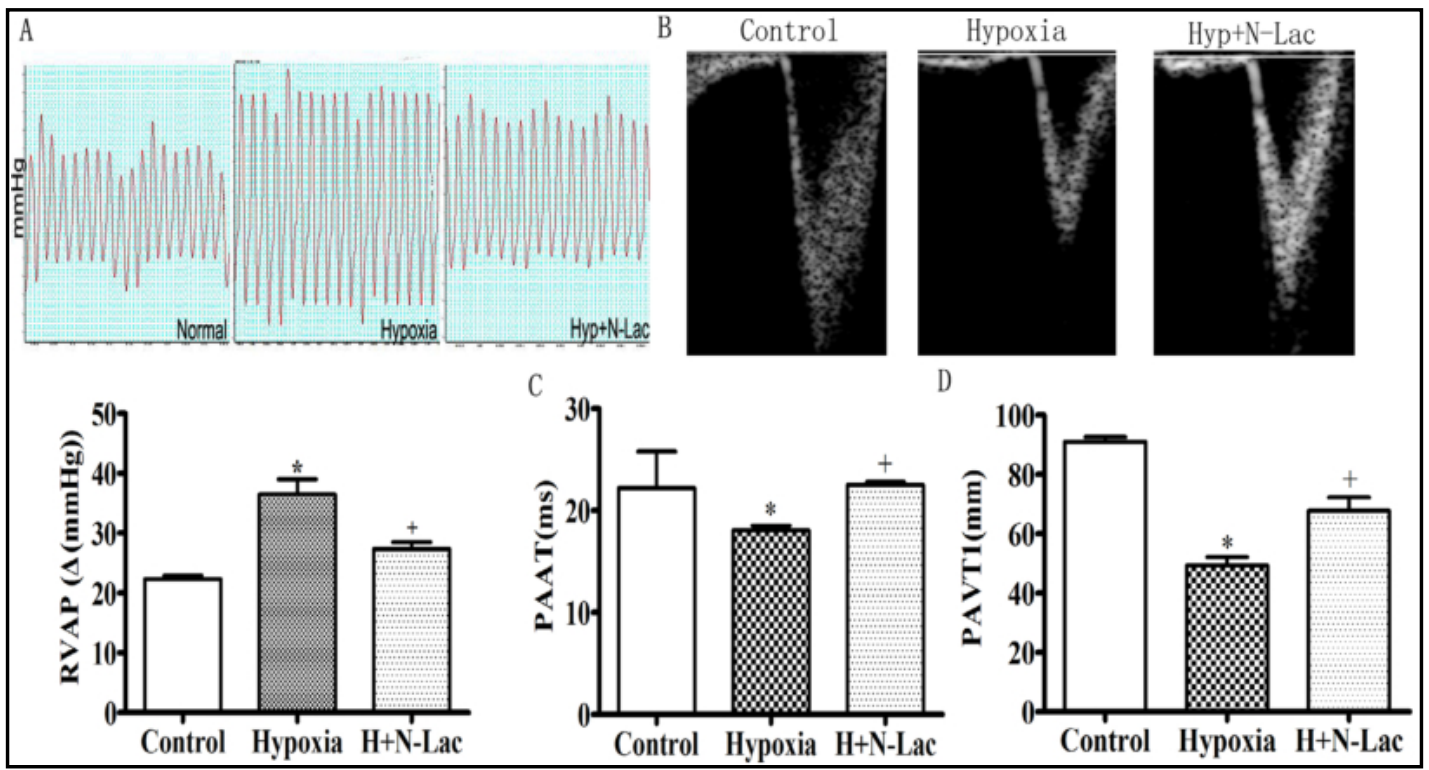

Fig. 1. Gal-3 regulates pulmonary arterial pressure. The role of Gal-3 in hypoxic rat pulmonary artery pressure. (A) Pulmonary vessel pressure was recorded using RM6240 through surgery of the right jugular vein. Pulmonary vessel images (B), pulmonary artery acceleration (PAAT) (C) and pulmonary arterial velocity time integral (PAVTI) (D) were monitored using the Ultrasound Biomicroscopy InviVue. The values are the mean \pm SEM of three independent experiments. ${ }^{*} \mathrm{p}<0.05$ versus control, $+\mathrm{p}<0.05$ versus hypoxia. 


\section{Cellular Physiology

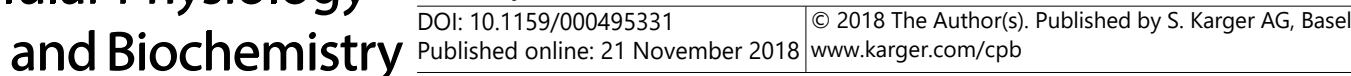

Fig. 2. Gal-3 is expressed in PAECs and is involved in PVR. Gal-3 was expressed in PAECs and mediated PVR. PVR in human lung tissues (A) and hypoxic rats with or without $\mathrm{N}$-Lac treatment (5 mg/kg was injected intraperitoneally once a day three times a week) (B) were detected using H\&E staining. Gal-3 mRNA expression in human lung tissues (C) and rat tissues (D) were measured using ISH. (E) Gal-3 protein expression and localization in rat vessels were determined using immunofluorescence. (F) Gal-3 protein expression in rat vessels was measured by Western blot. (G) The location of Gal-3 expression in cultured PAECs was detected by immunofluorescent labeling. Both Gal-3 mRNA (H) and protein (I) levels in hypoxiaexposed PAECs were analyzed by real-time PCR and Western blot, respectively. The values are the mean \pm SEM of six independent experiments. * $\mathrm{p}<0.05$ versus control, $+\mathrm{p}<0.05$

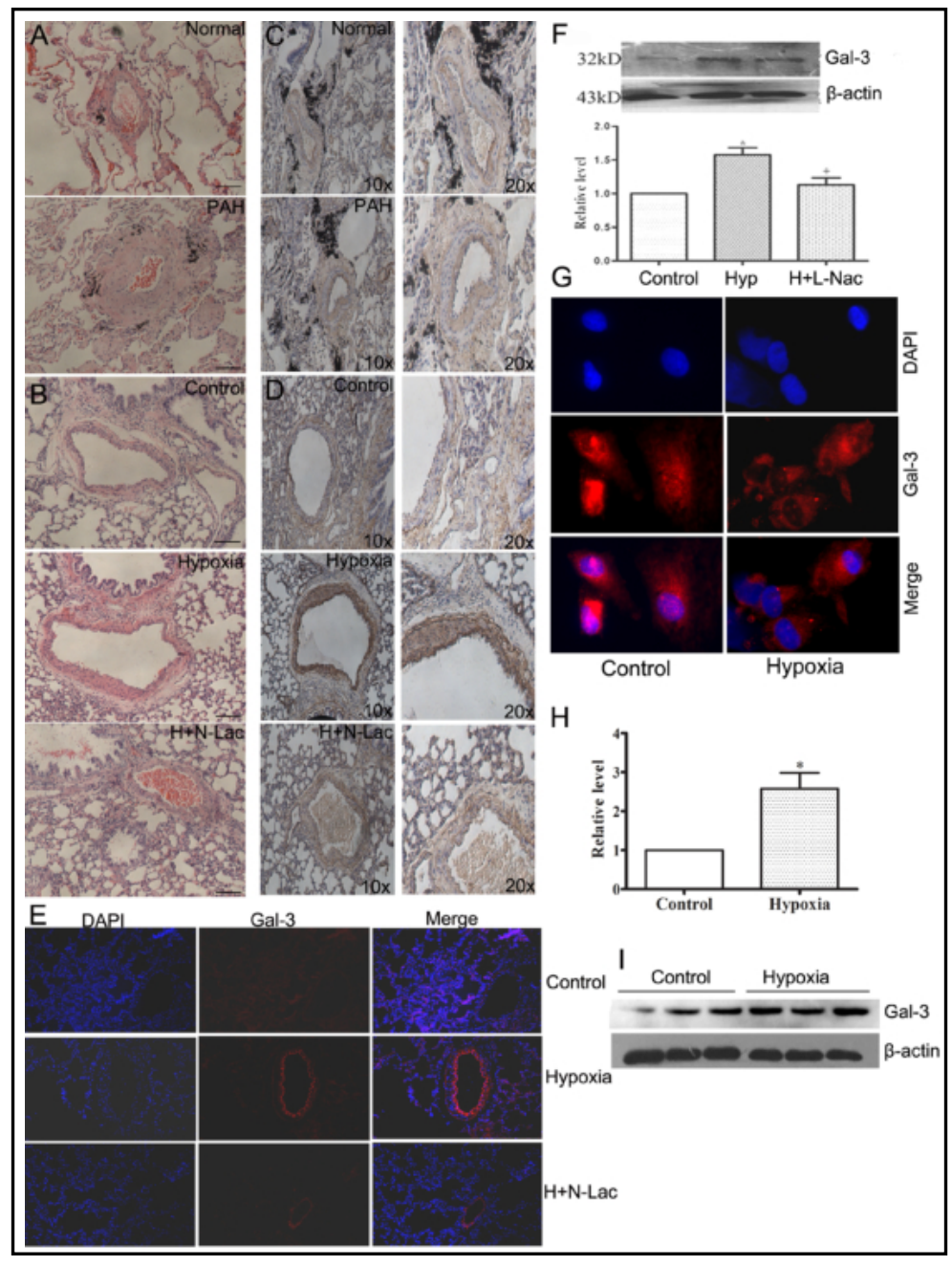
versus hypoxia.

colorimetric signals. Furthermore, we isolated and tested Gal-3 expression in vessel tissues, and the results indicated that hypoxia can enhance Gal-3 expression, as shown in Fig. 2F.

To further determine Gal-3 expression in vessel endothelial cells, we cultured PAECs in vitro. First, Gal-3 protein expression and cellular localization in PAECs were examined by immunofluorescence. As seen in Fig. 2G, there was strong fluorescence intensity of Gal-3 in the cytoplasm after cells were exposed to hypoxic stimulation, whereas Gal-3 was localized mainly to the nucleus in quiescent cells. Cells were collected to measure mRNA and protein expression levels of Gal-3 using real-time PCR and Western blot, respectively. The results showed that hypoxia enhanced both mRNA and protein levels of Gal-3 in PAECs (Fig. 2H and I).

\section{The effect of Gal-3 on PAEC proliferation}

To determine whether Gal-3 expression would promote PAEC proliferation, cells were treated with human recombinant Gal-3 $(5 \mu \mathrm{M})$. Cell viability was evaluated by MTT analysis. The results showed no obvious changes in cell viability with Gal-3 treatment (Fig. 3A). Additionally, the proliferation protein, PCNA, also remained unchanged after cell exposure to Gal-3 (Fig. 3B). Cell cycle assays revealed a depression of $S+G_{2} / M$ phase in Gal-3 treated cells by flow cytometry (Fig. 3C). Furthermore, cell cycle proteins, Cyclin E and CDK2, were consistently suppressed as shown in Fig. 3D. We also observed that cell nuclei exhibited abnormal transformations after Gal-3 treatment, as seen in Fig. 3E. 


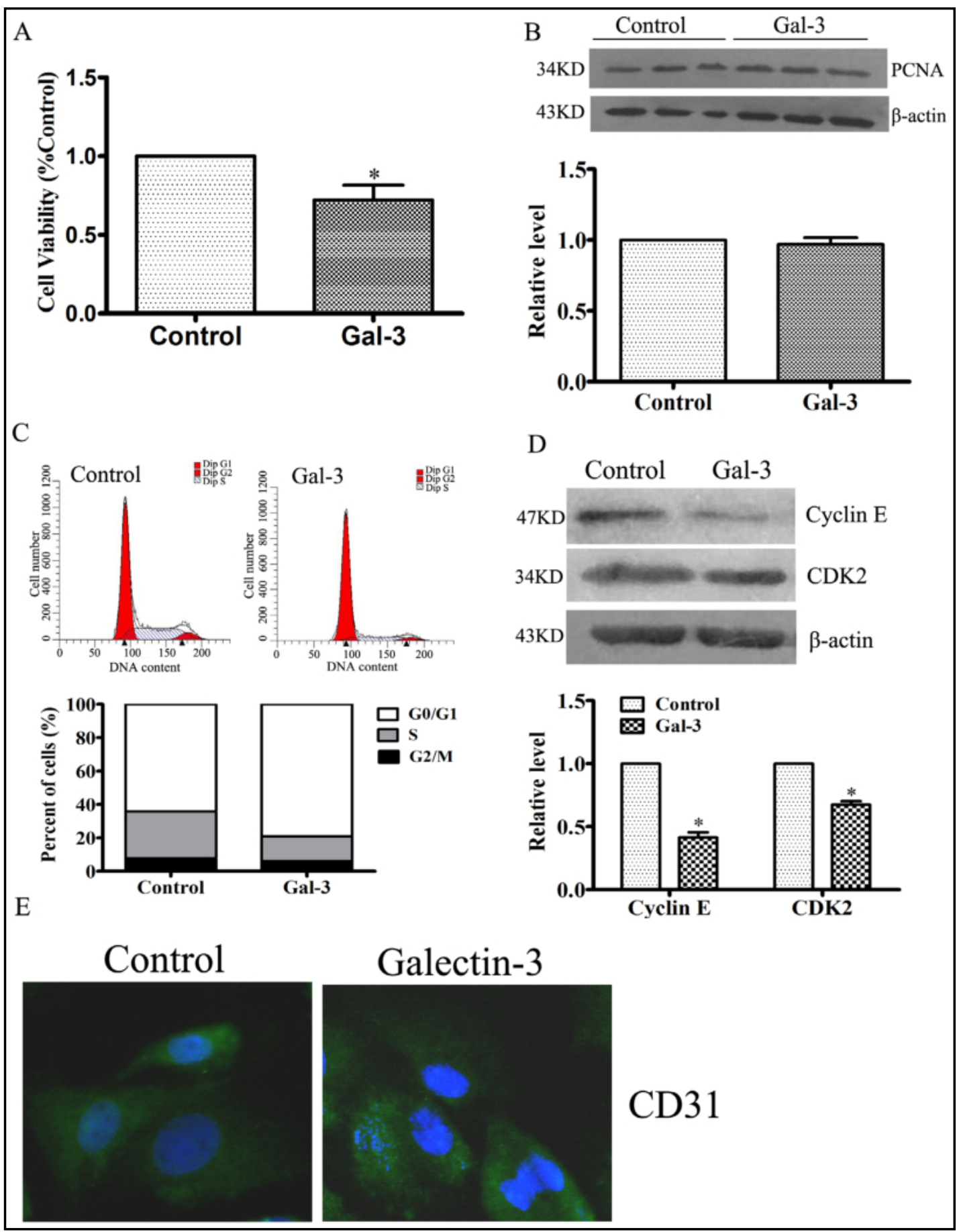

Fig. 3. The effect of Gal-3 on PAEC proliferation. The effect of Gal-3 on PAEC proliferation. PAECs were kept under normoxic conditions or treated with Gal-3 (5 $\mu \mathrm{M})$ for $7 \mathrm{~d}$. (A) The cell viability of PAECs after exposure to Gal-3 was analyzed by MTT. (B) The cell proliferation marker protein, PCNA, was measured by Western blot. (C) Cell cycle was detected using flow cytometry. (D) The protein levels of Cyclin E and CDK2 in PAECs were measured after Gal-3 treatment. (E) Cell morphology was shown by cell fluorescence staining. The values are the mean \pm SEM of six independent experiments. ${ }^{*} \mathrm{p}<0.05$ versus control. 


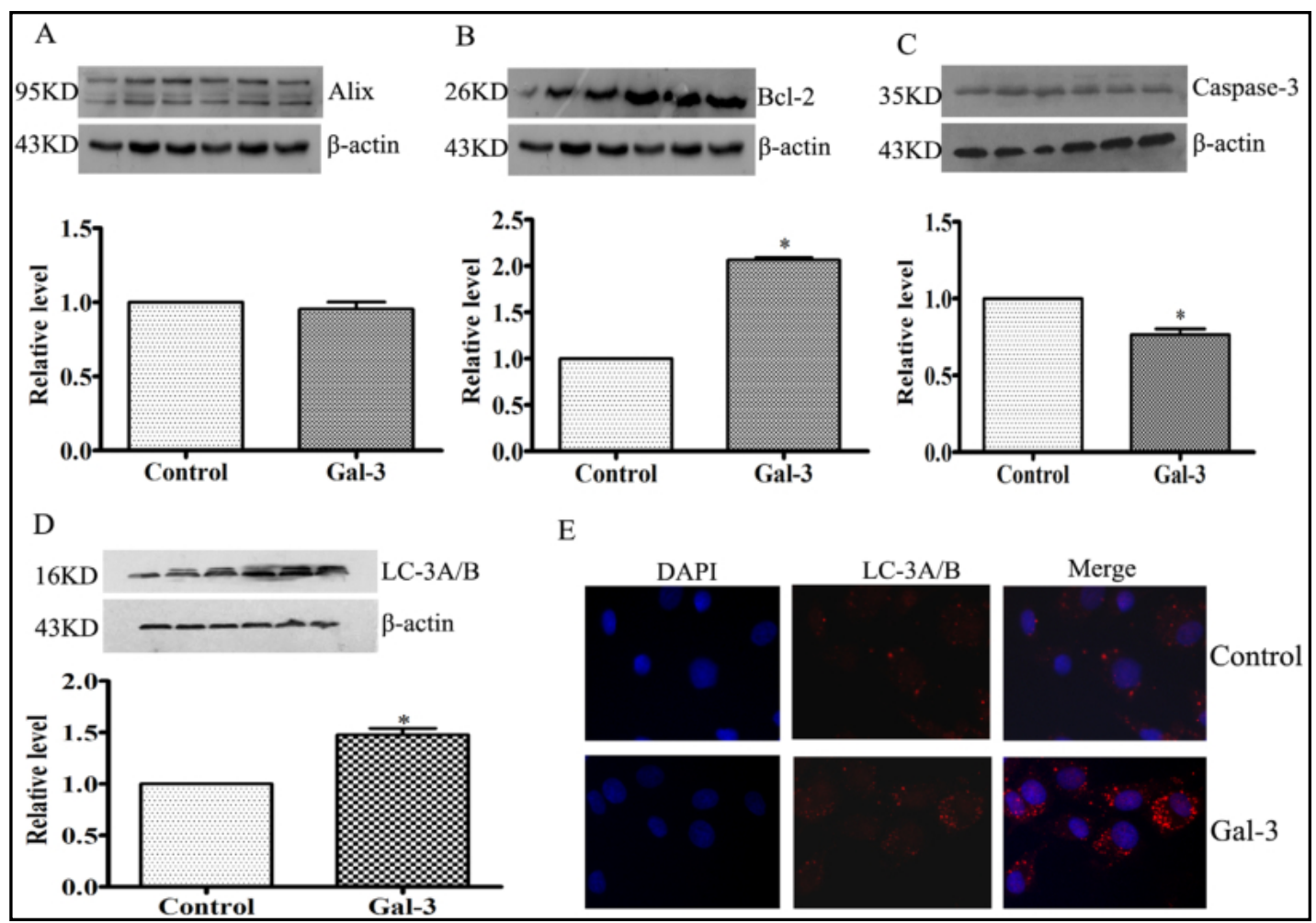

Fig. 4. The effect of Gal-3 on PAEC apoptosis. The effect of Gal-3 on PAEC apoptosis. PAECs were kept under normoxic conditions or treated with Gal-3 $(5 \mu \mathrm{M})$ for $7 \mathrm{~d}$. At the end of the incubation period, cell apoptosis was evaluated by determining the expression levels of apoptosis- related proteins, Alix (A), Bcl-2 (B), and caspase $3(\mathrm{C})$. Cell autophagy changes were assessed by LC3A/B protein expression using Western blot (D) and immunofluorescence staining (E) with LC-3A/B antibodies. The values are the mean \pm SEM of six independent experiments. ${ }^{*} \mathrm{p}<0.05$ versus control.

\section{The effect of Gal-3 on PAEC apoptosis}

Because Gal-3 did not influence PAEC proliferation, we hypothesized that Gal-3 may regulate cell apoptosis. As expected, Gal-3 increased $\mathrm{Bcl}-2$ and reduced caspase- 3 expression but did not have an effect on Alix in PAECs (Fig. 4A-C). This indicated that Gal-3 protected PAECs from apoptosis to a certain extent. By contrast, we found that Gal-3 promoted LC3B expression (Fig. 4D) and enhanced LC-3B fluorescent staining (Fig. 4E) in PAECs, which suggests that Gal-3 could induce cell autophagy.

\section{The effect of Gal-3 on PAEC transdifferentiation}

Recently, endothelial cell transformation was reported to be involved in vascular remodeling. Based on the effect of Gal-3 on cell proliferation and apoptosis in our study, we tested our hypothesis that Gal-3 may induce transformation in PAECs. Cells were treated with Gal-3 for $7 \mathrm{~d}$, and the results showed that PAECs differentiated into VSMCs as demonstrated by the expression of $\alpha$-SMA after treatment with Gal-3 protein (Fig. 5A). The transformation of PAECs was also confirmed by cell immunostaining. We observed a dramatic increase in the expression of $\alpha$-SMA in cultured PAECs with Gal-3 stimulation, while quiescent cells had no $\alpha$-SMA staining (Fig. 5B). In addition, we observed the expression of Calponin and Osteopontin, other phenotypic marker proteins of smooth muscle cells in PAECs. Further, Gal-3 elevated Calponin expression but not Osteopontin, as shown in Fig. 5C. In agreement, $\alpha$-SMA and Calponin displayed stronger staining by immunofluorescence in pulmonary artery intimal walls in hypoxic rat samples than in control vessels (Fig. 5D). Together, these data support the hypothesis that elevated endogenous Gal-3 likely drives endothelial cell transformation into VSMCs.

\section{KARGER}


Fig. 5. The effect of Gal-3 on PAEC transdifferentiation. The effect of Gal-3 on PAEC transdifferentiation. PAECs were kept under normoxic conditions or treated with Gal-3 $(5 \mu \mathrm{M})$ for $7 \mathrm{~d}$. At the end of the incubation period, (A) smooth muscle cell protein, $\alpha$-SMA, was detected. (B) Cell morphology was determined by immunofluorescence staining with $\alpha$-SMA antibodies. (C) Other smooth muscle cell marker proteins, Osteopontin and Calponin, were also detected after treatment with Gal-3. (D) Smooth muscle cell marker proteins, $\alpha$-SMA, Osteopontin and Calponin were detected in frozen rat lung sections using immunofluorescence staining. The values are the mean \pm SEM of six independent experiments. $* \mathrm{p}<0.05$ versus control, $+\mathrm{p}<0.05$ versus hypoxia or Gal-3.
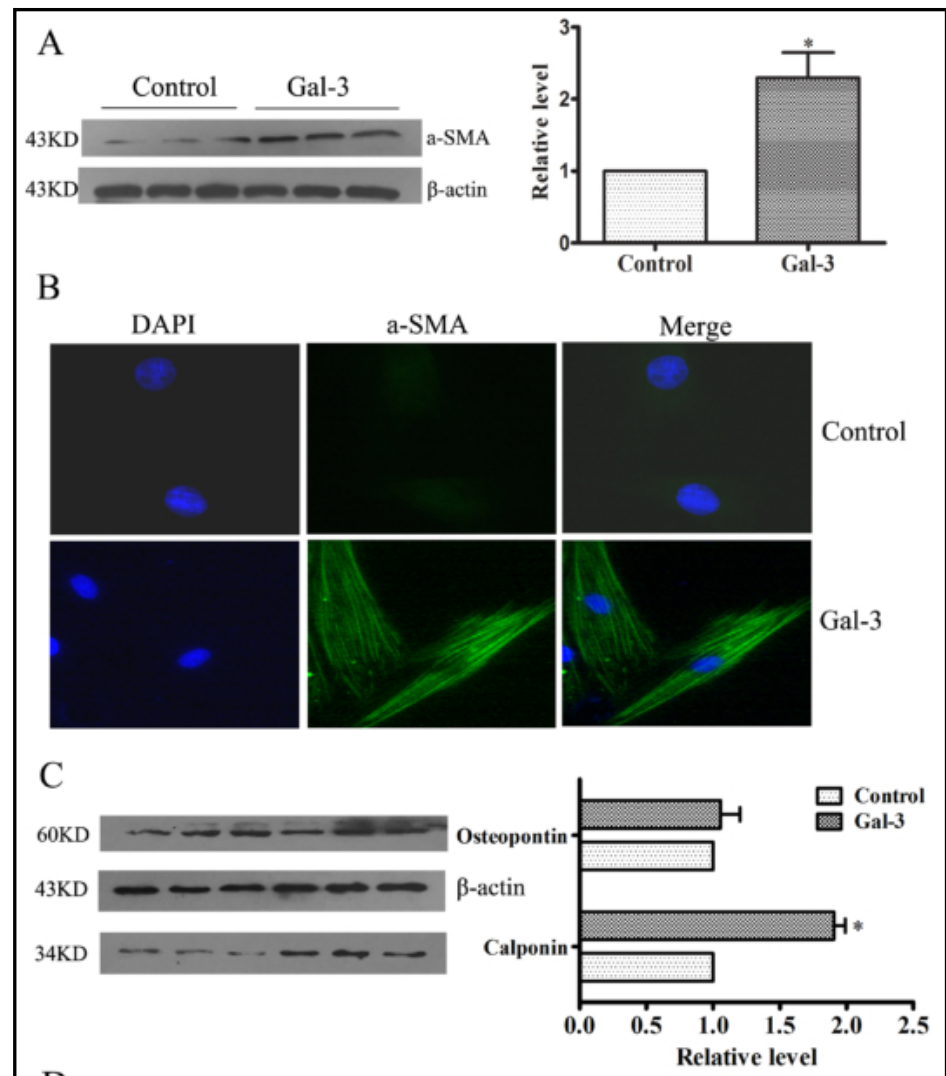

$\mathrm{D}$
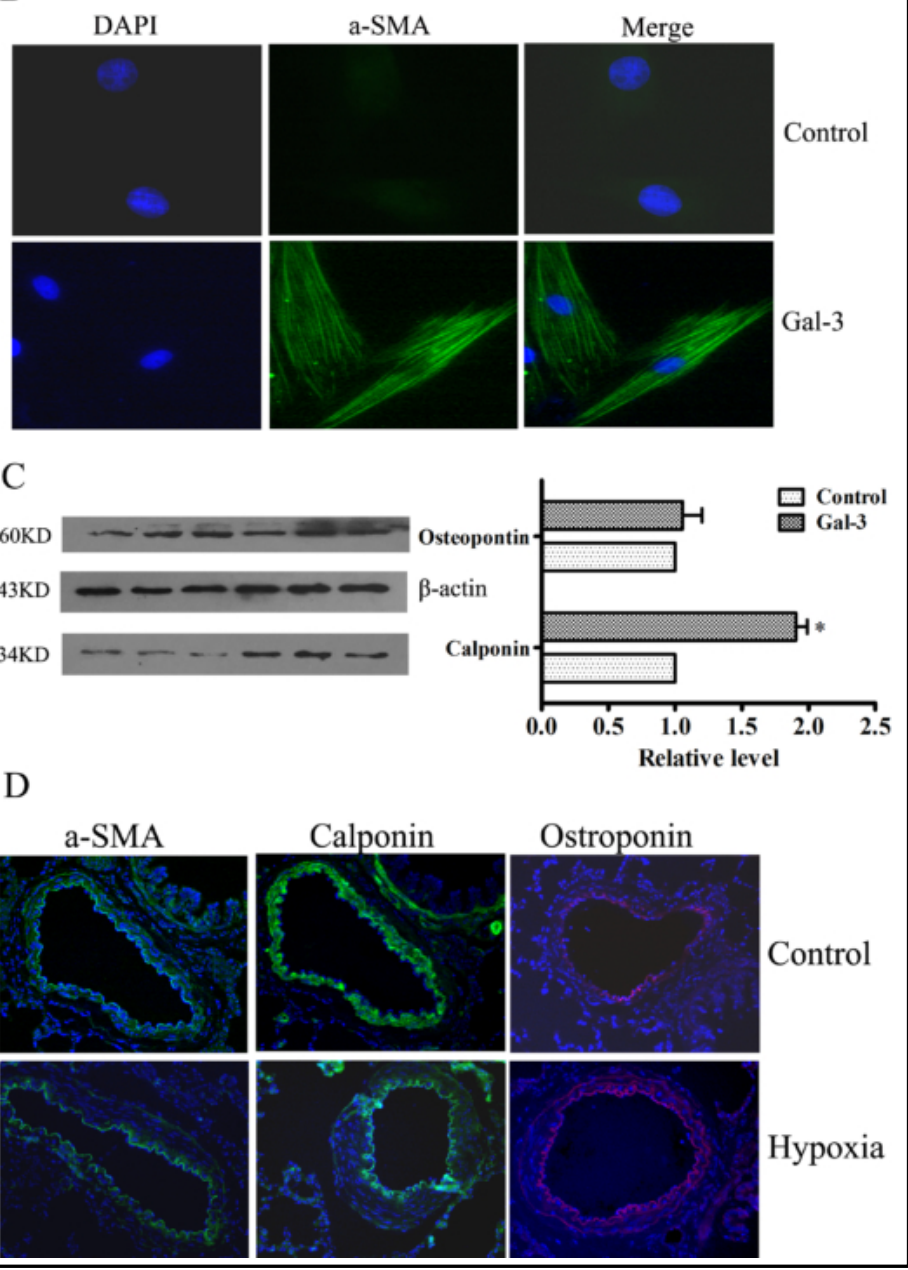

Jagged1/Notch1 was involved in Gal-3-induced conversion of PAECs into VSMCs

To study the pro-differentiation effect of Gal-3, we used siRNA interference to knockdown endogenous Gal-3 in PAECs. Indeed, silenced Gal-3 abolished the $\alpha$-SMA increase induced by hypoxia (Fig. 6A). Further, Gal-3 knockdown also attenuated the enhanced intensity of $\alpha$-SMA in hypoxic PAECs, as shown in Fig. 5B.

It is well-known that Jagged1-mediated activation of Notch1 signaling is important in the induction of endothelial-to-mesenchymal transdifferentiation (EndMT). Thus, we addressed the question of whether Jagged1/Notch1 activation participates in the Gal-3induced conversion of PAECs into VSMCs. To do this, we used the specific inhibitor of Notch1, DAPT. Our results showed that Gal-3 exposure induced an increase in Jagged 1 and activated Notch1 (Fig. 6C), while Gal-3-exposed PAECs in the presence of DAPT failed to display an increase in $\alpha$-SMA protein (Fig. 6D). In line with this finding, DAPT treatment inhibited the fluorescence intensity of $\alpha$-SMA induced by Gal-3 as shown in Fig. 6E. These results suggest that Jagged1/Notch1 activation is involved in the Gal-3-induced conversion of PAECs into VSMCs. 
Fig. 6. Jagged1/Notch1 is involved in Gal-3-induced conversion of PAECs into VSMCs. Jagged1/Notch1 is involved in Gal-3-induced conversion of PAECs into VSMCs. (A) PAECs transfected with siRNAs against Gal-3 (siRGal-3) or a nontargeting siRNA (siRNC) were exposed to hypoxia for $7 \mathrm{~d}$ and then $\alpha$-SMA expression was measured by Western blot and immunofluorescence staining (B). (C) PAECs were kept under normoxic conditions or treated with Gal-3 $(5 \mu \mathrm{M})$ for $7 \mathrm{~d}$. At the end of the incubation period, Jagged1/Notch1 pathway activity was measured by Western blot. PAECs were treated with Gal-3 $(5 \mu \mathrm{M})$ with or without pre-used 3,5-difluorophenylacetylL - a l a n y l - L - 2 phenylglycinetert-butyl ester (DAPT) (10 $\mu \mathrm{M}$, Notch signaling pathway inhibitor), and $\alpha$-SMA levels were determined
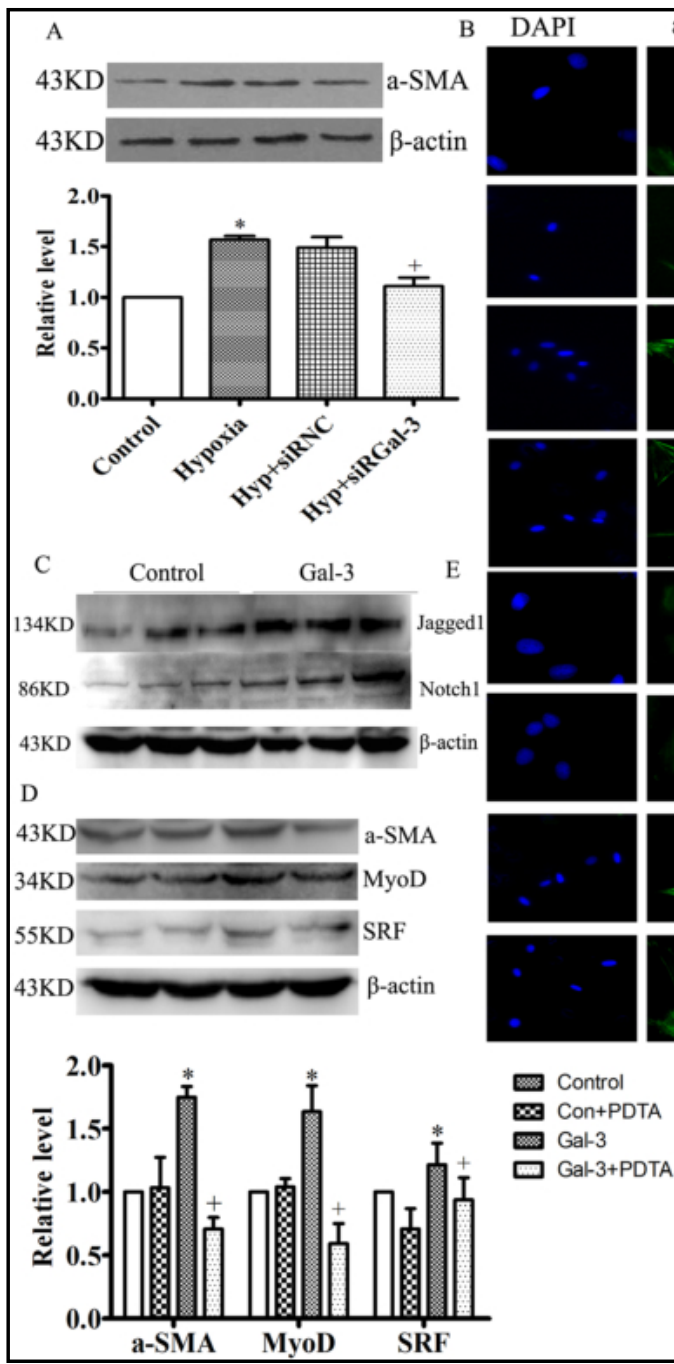
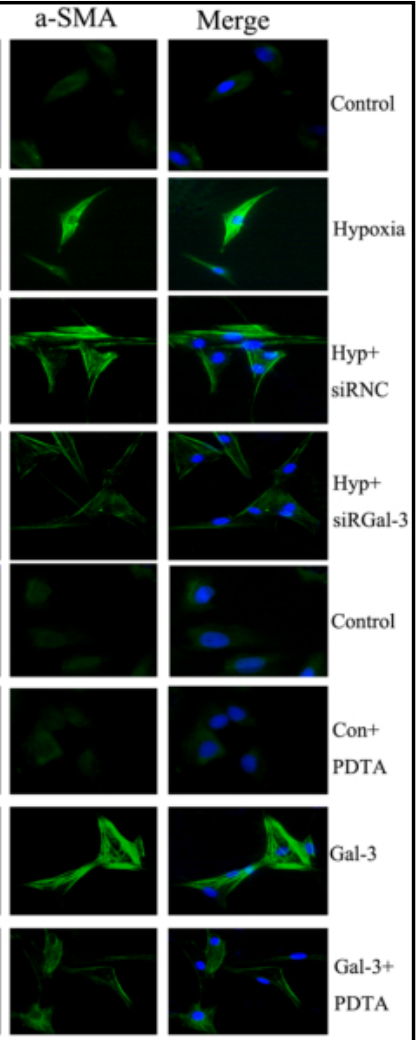

by Western blot (D) and

immunofluorescence staining (E). The values are the mean \pm SEM of six independent experiments. ${ }^{*} \mathrm{p}<0.05$ versus control, $+\mathrm{p}<0.05$ versus hypoxia.

\section{MyoD and SRF are required for Gal-3 induced $\alpha$-SMA expression}

Transcription factors in the bHLH family act in various differentiation processes, and class I bHLH proteins may activate the $\alpha$-SMA promoter, as some have reported previously [14]. To determine whether bHLH proteins could enhance $\alpha$-SMA expression under Gal-3 stimulation, we measured myogenic differentiation 1 (MyoD) expression after Gal-3 exposure in PAECs. The results showed that MyoD expression was increased in Gal-3-incubated cells (Fig. 7A). As myogenic bHLH proteins have been shown to physically interact with serum response factor (SRF) [15-16], we hypothesized that class I bHLH factors might activate $\alpha$-SMA transcription cooperatively with SRF in our present study. To test this, we determined SRF expression in Gal-3 treated PAECs. As shown in Fig. 7B, there was a greater increase in SRF expression after Gal-3 treatment. To further explore this, we performed experiments using a molecular biology strategy to achieve MyoD and SRF expression knockdown. To demonstrate the participation of MyoD and SRF in Gal-3-induced conversion of PAECs into VSMCs, PAECs were transfected with specific small interference RNAs (siRNAs) against MyoD (siRMyoD) or SRF (siRSRF). PAECs exposed to Gal-3 and transfected with a nontargeting sequence siRNA were used as a control (siRNC). These cells showed a decrease in the protein level of $\alpha$-SMA, which was similar to that in nontransfected, wild-type PAECs (Fig. 7C and D). 
Fig. 7. MyoD and SRF are required for Gal-3 induced $\alpha$-SMA expression. MyoD and SRF are required for Gal-3 induced $\alpha$-SMA expression. (A) PAECs were kept under normoxic conditions or treated with Gal-3 (5 $\mu \mathrm{M}$ ) for $7 \mathrm{~d}$. At the end of the incubation period, the protein levels of MyoD and SRF were measured by Western blot. (B) Gal-3-induced $\alpha$-SMA expression was measured after PAECs were transfected with siRMyoD or siRNC. (C)

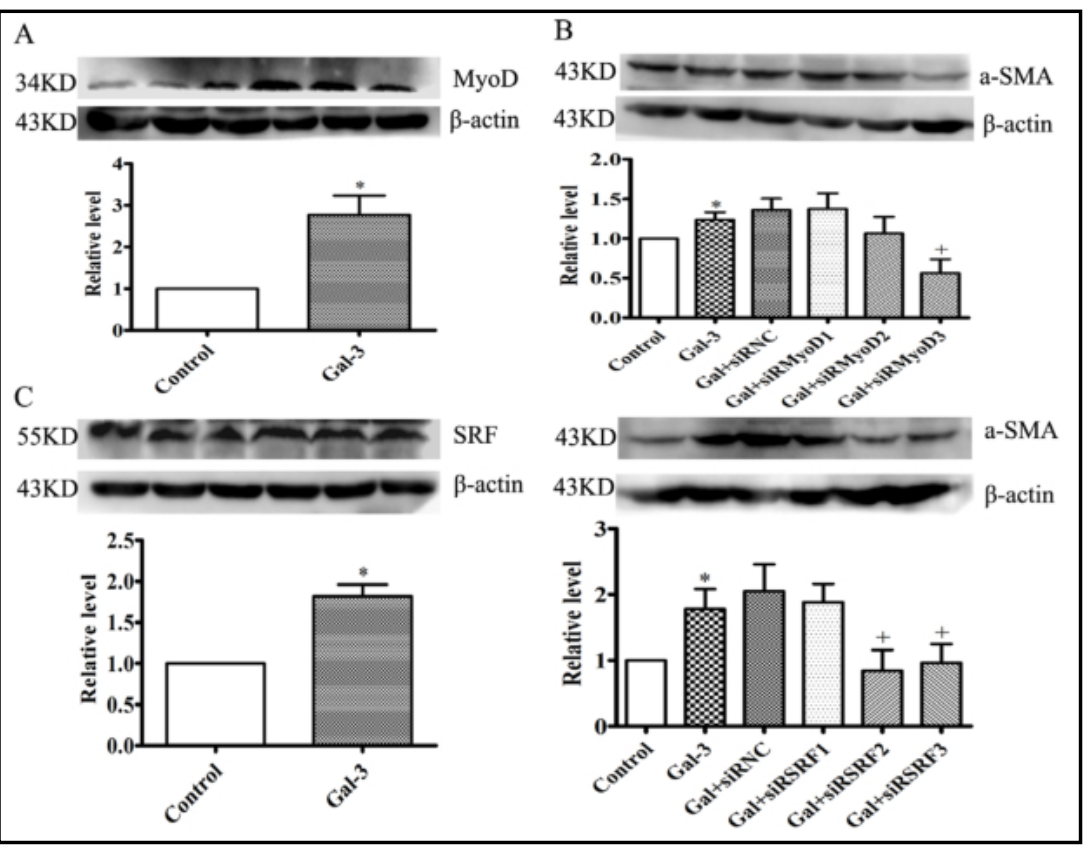
Gal-3-induced $\alpha$-SMA expression was measured after PAECs were transfected with siRSRF or siRNC. Cells treated with DAPT (10 $\mu \mathrm{M}), \mathrm{MyoD}(\mathrm{D})$ and SRF (E) were detected by Western blot, respectively. The values are the mean \pm SEM of six independent experiments. ${ }^{*} \mathrm{p}<0.05$ versus control.

Additionally, PAECs transfected with siRNC in the presence of Gal-3 did not show a significant change in the protein level of $\alpha$-SMA compared with Gal-3 treated cells. These results suggest that Gal-3 facilitates the cooperation between SRF and class I bHLH transcription factors for the regulation of $\alpha$-SMA transcription and PAECs transformation.

\section{Discussion}

Galectin-3, a member of the $\beta$-galactoside-binding gene family, is a multifunctional protein implicated in a variety of biological functions, such as proliferation, differentiation, migration and neovascularization. In recent years, Gal-3 was found to promote angiogenesis and tumor growth $[15,17]$. Inhibition of Gal-3 reduced atherosclerosis in apolipoprotein E-deficient mice [18]. In addition, Gal-3 has been used as a novel biomarker for better risk stratification in hypertrophic cardiomyopathy and the prognosis of heart failure [1, 19]. Furthermore, it has been demonstrated that elevated Gal-3 can be used as a method to predict mortality in PAH [20]. Our study also showed that inhibition of Gal-3 alleviated hypoxia-induced pulmonary artery pressure and ameliorated PVR. Hypoxia induced Gal-3 expression in the pulmonary vessel adventitia and intima suggests that Gal-3 may control vessels by regulating the activities of fibroblasts and endothelial cells.

The action of Gal-3 is mediated by intracellular Gal-3, especially in the nucleus, or secreted Gal-3 [21]. Secreted Gal-3 regulates cell adhesion and migration through cell-cell and cell-extracellular matrix interactions $[16,22]$. Reports have shown that Gal-3 produced by tumors may induce macrophage migration and promote angiogenesis and tumor growth [15]. On the other hand, Gal-3 has been shown to be a component of heterogeneous nuclearribonuclear protein complexes that are used for pre-mRNA splicing as a mechanism to control cell cycling and prevent apoptosis, possibly through interactions with Bcl-2 family members [23-24]. Previous studies on endothelial cells indicated that Gal-3 stimulated proliferation and angiogenesis $[15,25]$. In contrast, we found that Gal-3 depressed PAEC proliferation and lowered cell apoptosis. As several studies demonstrated that endothelial 


\section{Cellular Physiology Cell Physiol Biochem 2018;51:763-777

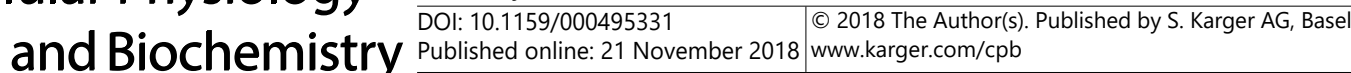 \\ Zhang et al.: Galectin-3 Regulates Endothelial Cell Transdifferentiation}

cells can differentiate into SMCs $[23,26]$, and human umbilical vein endothelial cells are capable of transdifferentiating into beating cardiomyocytes [27], it would be interesting to explore whether Gal-3 can induce PAECs transformation.

EndMT is increasingly being viewed as an important biological process in development and disease. Endothelial-derived mesenchymal cells may be involved in the development of neointimal lesions in transplant atherosclerosis and restenosis [28]. Epithelial-mesenchymal transition (EMT) was shown to be involved in the development and aggressiveness of tumors [29-30]. Studies on embryonic avian aortic and human pulmonary vascular development demonstrated that the endothelium itself may be the source of at least some SMCs in the arteries [26, 31-32]. In this study, we described the endothelial-smooth muscle transdifferentiation in pulmonary artery intima under Gal-3 stimulation, which induced a contractive phenotype as demonstrated by the expression of $\alpha$-SMA and Calponin but not Osteopontin.

In PAH, the elevation of pulmonary arterial pressure is due to a combination of sustained vasoconstriction and structural remodeling, significant components of remodeling in $\mathrm{PAH}$ include medial thickening in muscularized pulmonary vessels, as well as extension of muscularization distally to small pulmonary arteries [33-34], both of which are associated with enhanced proliferation [35] and migration [36] of PASMCs. The sources of PASMCs may be proliferation or another type of cell transformation. As we previously reported, the adventitial fibroblasts turned into SMCs under hypoxia exposure [2, 37]. In this study, we demonstrated that Gal-3 is able to induce conversion of PAECs into VSMCs via an EndMT-like process, which may be important to small pulmonary vessel muscularity in PAH.

bHLH members are transcription factors that function in various differentiation processes, as either positive or negative regulators, and play key roles in different developmental events such as neurogenesis and myogenesis [38]. Some have demonstrated a potential role for class I bHLH factors and their inhibitors, Id and Twist, in SM-actin regulation [26]. Consequently, we investigated the effect of MyoD in Gal-3-induced $\alpha$-SMA expression. Consistent with these reports, $\alpha$-SMA was activated by Gal-3 enhanced-MyoD in our study.

SRF plays a general role in controlling the expression of multiple SMC genes during differentiation and phenotypic modulation [39]. The activation of the $\alpha$-SMA promoter may be due, at least in part, to the recruitment and interaction (direct or indirect) of acquired SRF with endogenous class I bHLH factors, which lends further support for a functional cooperation between SRF and class I bHLH factors in the regulation of SM-actin transcription $[13,40]$. We found that SRF increased with Gal-3 treatment in PAECs, while after SRF knockdown, Gal-3-induced $\alpha$-SMA expression was decreased. These results demonstrate that SRF is an important factor in regulating $\alpha$-SMA expression during the EndMT process.

It is believed that the EndMT process is activated and regulated by various stimuli, transcription factors and signal transduction pathways. To date, Notch signaling pathways have been proven to be key regulators in the induction of EMT and EndMT processes [28, 41]. Notch activation in endothelial cells results in morphological, phenotypical and functional changes that are consistent with mesenchymal transformation. Moreover, it is also known that Jagged1-mediated activation of Notch signaling is important in the induction of EMT [42]. Thus, it would be interesting to test whether Gal-3-induced EndMT is inhibited by a Notch1 inhibitor. We show here that Gal-3 activated the Jagged1 and Notch1 pathways, while DAPT blocked Gal-3-induced transcription factors, MyoD, SRF and EndMT in PAECs.

\section{Conclusion}

The results shown here provide evidence that Gal-3 is a crucial factor in inducing PAEC transformation into VSMCs through Jagged1/Notch1 dependent MyoD and SRF expression in this pathological condition. These findings will be useful in improving therapeutic strategies for PVR and PAH. 


\section{Cellular Physiology Cell Physiol Biochem 2018;51:763-777 and Biochemistry \begin{tabular}{l|l} 
DOI: 10.1159/000495331 2018 The Author(s). Published by S. Karger AG, Basel \\
Published
\end{tabular}

\section{Abbreviations}

PAH (pulmonary artery hypertension); Gal-3 (galectin-3); PVR (pulmonary vascular remodeling); PASMCs (pulmonary artery smooth muscle cells); PA-VTI (pulmonary arterial velocity time integral); PAAT (pulmonary artery acceleration); DAB (3, 3-diaminobenzidine); EndMT (endothelial-to-mesenchymal transition); PAECs (pulmonary artery endothelial cells); DAPI (4',6-Diamidino-2-phenylindole); BSA (bovine serum albumin); MTT (3-[4, 5-dimethylthiazol-2-yl]-2, 5-diphenyl-tetrazolium bromide).

\section{Acknowledgements}

This work was supported by the National Natural Science Foundation of China (81300036, 31600956), Natural Science Foundation of Fujian Province, China (Grant No. 2018J01828; No. 2018J06021), Young and Middle-aged Backbone Personnel Training Project of Fujian Health and Family Planning Commission (2018-ZQN-59) and the Fujian Medical University Talent Startup Fund (XRCZX2017003, XRCZX2017004).

\section{Disclosure Statement}

The authors have declared that no competing interests exist.

\section{References}

1 Stenmark KR, Nozik-Grayck E, Gerasimovskaya E, Anwar A, Li M, Riddle S, Frid M: The adventitia: Essential role in pulmonary vascular remodeling. Compr Physiol 2011;1:141-161.

2 Zhang L, Li Y, Chen M, Su X, Yi D, Lu P, Zhu D: 15-LO/15-HETE mediated vascular adventitia fibrosis via p38 MAPK-dependent TGF- $\beta$. J Cell Physiol 2014;229:245-257.

-3 Coll-Bonfill N, Musri MM, Ivo V, Barberà JA, Tura-Ceide 0: Trans- differentiation of endothelial cells to smooth muscle cells play an important role in vascular remodelling. Am J Stem Cells 2015;4:13-21.

-4 Taher M, Nakao S, Zandi S, Melhorn MI, Hayes KC, Hafezi-Moghadam A: Phenotypic transformation of intimal and adventitial lymphatics in atherosclerosis: a regulatory role for soluble VEGF receptor 2. FASEB J 2016;30:2490-2499.

5 Malsiner CC, Schmitz M, Horch RE, Keller AK, Leffler M: Vessel transformation in chronic wounds under topical negative pressure therapy: an immunohistochemical analysis. Int Wound J 2015;2:501-509.

6 Amin HZ, Amin LZ, Wijaya IP: Galectin-3: a novel biomarker for the prognosis of heart failure. Clujul Med 2017;90:129-132.

-7 Maiolino G, Rossitto G, Pedon L, Cesari M, Frigo AC, Azzolini M, Plebani M, Rossi GP: Galectin-3 predicts long-term cardiovascular death in high-risk patients with coronary artery disease. Arterioscler Thromb Vasc Biol 2015;35:725-732.

8 Guo S and Feng Z: Galectin-3 mediates the effect of PDGF on pulmonary arterial hypertension. Int J Clin Exp Med 2015;8:15302-15307.

-9 Wang XY, Wang YL, Zhang JB, Guan X, Chen MG, Li YM, Zhang L: Galectin-3 contributes to vascular fibrosis in monocrotaline-induced pulmonary arterial hypertension rat model. J Biochem Mol Toxicol DOI: 10.1002/ jbt.21879.

10 Hao M, Li M, Li W: Galectin-3 inhibition ameliorates hypoxia-induced pulmonary artery hypertension. Mol Med Rep 2017;15:160-168.

11 Liang S, Yu H, Chen X, Shen T, Cui Z, Si G, Zhang J, Cheng Y, Jia S, Song S, Zhang X, Yu X: PDGF-BB/KLF4/VEGF Signaling Axis in Pulmonary Artery Endothelial Cell Angiogenesis. Cell Physiol Biochem 2017;41:23332349. 


\section{Cellular Physiology Cell Physiol Biochem 2018;51:763-777 and Biochemistry \begin{tabular}{l|l|l}
\hline DOI: 10.1159/000495331 2018 The Author(s). Published by S. Karger AG, Basel \\
Published
\end{tabular}

12 Li Y, Zhang L, Wang X, Chen M, Liu Y, Xing Y, Wang X, Gao S, Zhu D: Elk-1-mediated15-lipoxygenase expression is required for hypoxia-induced pulmonary vascular adventitial fibroblast dynamics. Acta Physiol (Oxf) 2016;218:276-289.

13 Xu Y, Bei Y, Shen S, Zhang J, Lu Y, Xiao J, Li X: MicroRNA-222 Promotes the Proliferation of Pulmonary Arterial Smooth Muscle Cells by Targeting P27 and TIMP3. Cell Physiol Biochem 2017;43:282-292.

14 Kumar MS, Hendrix JA, Johnson AD, Owens GK: Smooth muscle alpha-actin gene requires two E-boxes for proper expression in vivo and is a target of class I basic helix-loop-helix proteins. Circ Res 2003;92:840847.

-15 Funasaka T, RazA, Nangia-Makker P: Galectin-3 in angiogenesis and metastasis. Glycobiology 2014;24:886891.

16 Ge XN, Ha SG, Liu FT, Rao SP, Sriramarao P: Eosinophil-expressed galectin-3 regulates cell trafficking and migration. Front Pharmacol DOI: 10.3389/fphar.2013.00037.

-17 Fortuna-Costa A, Gomes AM, Kozlowski EO, Stelling MP, Pavão MS: Extracellular galectin-3 in tumor progression and metastasis. Front Oncol DOI: 10.3389/fonc.2014.00138.

18 MacKinnon AC, Liu X, Hadoke PW, Miller MR, Newby DE, Sethi T: Inhibition of galectin-3 reduces atherosclerosis in apolipoprotein E-deficient mice. Glycobiology 2013;23:654-663.

19 YakarTülüce S, Tülüce K, Çil Z, Emren SV, Akyıldız Zİ, Ergene O: Galectin-3 levels in patients with hypertrophic cardiomyopathy and its relationship with left ventricular mass index and function. Anatol J Cardiol 2016;6:344-348.

20 Mazurek JA, Horne BD, Saeed W, Sardar MR, Zolty R: Galectin-3 Levels Are Elevated and Predictive of Mortality in Pulmonary Hypertension. Heart Lung Circ 2017;26:1208-1215.

-21 Funasaka T, Raz A, Nangia-Makker P: Nuclear transport of galectin-3 and its therapeutic implications. Semin Cancer Biol 2014;27:30-38.

-22 Quattroni P, Li Y, Lucchesi D, Lucas S, Hood DW, Herrmann M, Gabius HJ, Tang CM, Exley RM: Galectin-3 binds Neisseria meningitidis and increases interaction with phagocytic cells. Cell Microbiol 2012;14:16571675.

23 Arciniegas E, Sutton AB, Allen TD, Schor AM: Transforming growth factor-1 promotes the differentiation of endothelial cells into smooth muscle-like cells in vitro. J Cell Sci 1992;103:521-529.

24 Yang RY, Hsu DK, Liu FT: Expression of galectin-3 modulates T-cell growth and apoptosis. Proc Natl Acad Sci USA 1996;93:6737-6742.

25 Nangia-Makker P, Honjo Y, Sarvis R, Akahani S, Hogan V, Pienta KJ, Raz A: Galectin-3 induces endothelial cell morphogenesis and angiogenesis. Am J Pathol 2000;56:899-909.

26 Frid MG, Kale VA, Stenmark KR: Mature vascular endothelium can give rise to smooth muscle cells via endothelial-mesenchymal transdifferentiation: in vitro analysis. Circ Res 2002;90:1189-1196.

27 Condorelli G, Borello U, De Angelis L, Latronico M, Sirabella D, Coletta M, Galli R, Balconi G, Follenzi A, Frati G, Cusella De Angelis MG, Gioglio L, Amuchastegui S, Adorini L, Naldini L, Vescovi A, Dejana E, Cossu G: Cardiomyocytes induce endothelial cells to trans-differentiate into cardiac muscle: implications for myocardium regeneration. Proc Natl Acad Sci USA 2001;8:10733-10738.

-28 Beranek JT, Cavarocchi NC: Undifferentiated vascular endothelial cells in coronary allograft atherosclerosis. Internatl J Cardiol 1990;28:127-128.

29 Scheinowitz M, Shou M, Banai S, Gertz SD, Lazarous DF, Unger EF: Neointimal proliferation in canine coronary arteries. A model of restenosis permitting local and continuous drug delivery. Lab Invest 1994;71:813-819.

30 Wang Z, Li Y, Kong D, Sarkar FH: The role of Notch signaling pathway in epithelial-mesenchymal transition (EMT) during development and tumor aggressiveness. Curr Drug Targets 2010;11:745-751.

-31 Arciniegas E, Servin M, Arguello C, Mota M: Development of the aorta in the chick embryo: structural and ultrastructural study. Atherosclerosis 1989;76:219-235.

32 Hall SM, Hislop AA, Pierce CM, Haworth SG: Prenatal origins of human intrapulmonary arteries: formation and smooth muscle maturation. Am J Respir Cell Mol Biol 2000;23:194-203.

-33 Chazova I, Loyd JE, Zhdanov VS, Newman JH, Belenkov Y, Meyrick B: Pulmonary artery adventitial changes and venous involvement in primary pulmonary hypertension. Am J Pathol 1995;146:389-397.

-34 Tuder RM: Pathology of pulmonary arterial hypertension. Semin. Respir Crit Care Med 2009;30:376-385. 


\section{Cellular Physiology Cell Physiol Biochem 2018;51:763-777 and Biochemistry DOl: 10.1159/000495331 2018 (0) 2018 The Author(s). Published by S. Karger AG, Basel

-35 Falcetti E, Hall SM, Phillips PG, Patel J, Morrell NW, Haworth SG, Clapp LH: Smooth muscle proliferation and role of the prostacyclin (IP) receptor in idiopathic pulmonary arterial hypertension. Am J Respir Crit Care Med 2010;182:1161-1170.

-36 Paulin R, Meloche J, Courboulin A, Lambert C, Haromy A, Courchesne A, Bonnet P, Provencher S, Michelakis ED, Bonnet S: Targeting cell motility in pulmonary arterial hypertension. EurRespir J 2014;43:531-544.

-37 Zhang L, Li YM, Liu YM, Wang XY, Chen MG, Xing Y, Zhu DL: STAT3-mediated MMP-2 expression is required for 15-HETE-induced vascular adventitial fibroblast migration. J Steroid Biochem Mol Biol 2015;149:106117.

-38 Weintraub H, Tapscott SJ, Davis RL, Thayer MJ, Adam MA, Lassar AB, Miller AD: Activation of musclespecific genes in pigment, nerve, fat, liver, and fibroblast cell lines by forced expression of MyoD. Proc Natl Acad Sci USA 1989;86:5434-5438.

39 Park C, Hennig GW, Sanders KM, Cho JH, Hatton WJ, Redelman D, Park JK, Ward SM, Miano JM, Yan W, Ro S: Serum response factor-dependent MicroRNAs regulate gastrointestinal smooth muscle cell phenotypes. Gastroenterology 2010:141:164-175.

-40 Groisman R, Masutani H, Leibovitch MP, Robin P, Soudant I, Trouche D, Harel-Bellan A: Physical interaction between the mitogen-responsive serum response factor and myogenic basic-helix-loop-helix proteins. J Biol Chem 1996;271:5258-5264.

41 Li C, Dong F, Jia Y, Du H, Dong N, Xu Y, Wang S, Wu H, Liu Z, Li W: Notch signal regulates corneal endothelialto-mesenchymal transition. Am J Pathol 2013;183:786-795.

42 Zavadil J, Cermak L, Soto-Nieves N, Böttinger EP: Integration of TGF-beta/Smad and Jagged1/Notch signalling in epithelial-to-mesenchymal transition. EMBO J 2004;3:1155-1165. 